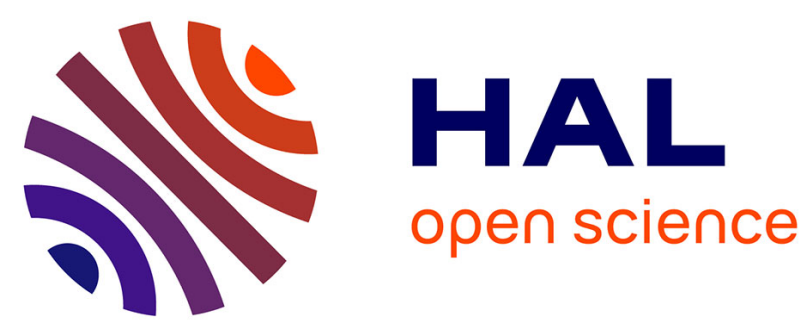

\title{
The true prognosis of resected distal cholangiocarcinoma
}

Laetitia Courtin-Tanguy, Michel Rayar, Damien Bergeat, Aude Merdrignac, Yann Harnoy, Karim Boudjema, B. Meunier, Laurent Sulpice

\section{To cite this version:}

Laetitia Courtin-Tanguy, Michel Rayar, Damien Bergeat, Aude Merdrignac, Yann Harnoy, et al.. The true prognosis of resected distal cholangiocarcinoma. Journal of Surgical Oncology, 2016, 113 (5), pp.575-80. 10.1002/jso.24165 . hal-01263109

\section{HAL Id: hal-01263109 \\ https://hal-univ-rennes1.archives-ouvertes.fr/hal-01263109}

Submitted on 28 Jan 2016

HAL is a multi-disciplinary open access archive for the deposit and dissemination of scientific research documents, whether they are published or not. The documents may come from teaching and research institutions in France or abroad, or from public or private research centers.
L'archive ouverte pluridisciplinaire HAL, est destinée au dépôt et à la diffusion de documents scientifiques de niveau recherche, publiés ou non, émanant des établissements d'enseignement et de recherche français ou étrangers, des laboratoires publics ou privés. 


\section{The true prognosis of resected distal cholangiocarcinoma}

L. Courtin-Tanguy, $\mathrm{MD}^{1,2,3}$, M. Rayar, $\mathrm{MD}^{1,2,4}$, D. Bergeat, $\mathrm{MD}^{1,2,3}$, A. Merdrignac, $\mathrm{MD}^{1,2,3}$, Y.

Harnoy, $\mathrm{MD}^{1,2,3}$, K. Boudjema, MD, $\mathrm{PhD}^{1,2,4}$, B. Meunier, $\mathrm{MD}^{1,2}$ and L. Sulpice, $\mathrm{MD}, \mathrm{PhD}^{1,2,3,4}$

${ }^{1}$ CHU Rennes, Service de Chirurgie Hépatobiliaire et Digestive, F-35033 Rennes, France

${ }^{2}$ Université Rennes1, Faculté de médecine, F-35043 Rennes, France

${ }^{3}$ INSERM, U991, Foie métabolismes et cancer, F-35033 Rennes, France

${ }^{4}$ INSERM, U1414, Centre d'investigation Clinique, F-35033 Rennes, France

Correspondence: Pr. L. Sulpice, M.D. Ph.D.

E-mail: laurent.sulpice@chu-rennes.fr

Phone number: +33299284265

Fax: +33299284129

Disclaimers: No disclaimers

Conflicts of interest: The authors have no conflicts of interest to declare.

Funding: The study received no external support.

Word count for the text: 3095

Word count for the abstract: 200

Authors' contributions: LCT and LS conceived and designed the study, performed the analysis and interpretation of the data, and wrote and finalized the manuscript. LCT, DB and AM collected the data. MR performed the statistical analysis. KB and LS analysed and interpreted the data and revised the manuscript. BM and LS revised the manuscript and gave final approval for publication.

Running Head: Prognosis of distal cholangiocarcinoma 


\section{SYNOPSIS}

Previously published studies found a better survival for DCC than for pancreatic ductal adenocarcinomas (PDAC), but those results were based on uncontrolled cohorts analyses. Our work studied specifically prognosis of DCC, comparing it PDAC, by a propensity score.

\section{KEY WORDS}

Distal cholangiocarcinoma, recurrence, prognosis 


\section{ABSTRACT}

Background : Prognosis of distal cholangiocarcinoma (DCC) after pancreaticoduodenectomy (PD) remains poorly assessed. The aims of this study were to describe the oncological results of PD in DCC and to compare its prognosis to pancreatic ductal adenocarcinoma (PDAC).

Methods: All PD for periampullary carcinoma performed between January 2000 and March 2013 were extracted from a prospective database. Risk factors likely to influence overall (OS) and disease-free (DFS) survivals of DCC were assessed by multivariable analyses. The DCC and PDAC prognoses were compared after matching using propensity score (nearest neighbour matching).

Results: Of the 290 patients analysed, 56 had DCC, with a mean age of $65 \pm 15$ years. The median OS was 36.9 months. Recurrence occurred in 35 patients (67\%), mostly in the liver (37\%). The median DFS was 14.6 months. Combined organ resection was an independent risk factor for worse OS and DFS ( $\mathrm{p}=0.01$ and $\mathrm{p}=0.001$, respectively). Matching analysis found no significant difference between DCC and PDAC in terms of OS $(p=0.284)$ or DFS $(\mathrm{p}=0.438)$.

Conclusion: This first propensity analysis demonstrated that DCC and PDAC have the same prognosis, linked to the high rate of early recurrence, particularly associated with the need for combined organ resection. 


\section{INTRODUCTION}

Distal cholangiocarcinoma (DCC) is an epithelial tumour developed from the lower third of the extrahepatic bile duct and accounts for 30 to 40 percent of all cholangiocarcinomas (1) and 11 to $20 \%$ of all periampullary cancers $(2,3)$. The typical risk factors of DCC are male gender, older age and chronic biliary inflammation (4). Two pre-cancerous lesions have been identified: intraepithelial neoplasms and intraductal and papillary tumours (5). The only potentially curative treatment for DCC is pancreaticoduodenectomy (PD), and chemotherapy can achieve a partial response or stabilize the disease in patients who are unresectable $(6,7)$. In contrast to pancreatic ductal adenocarcinomas (PDAC), the administration of adjuvant chemotherapy following curative PD for DCC remains controversial and is currently under debate. Even when surgery with curative intent is performed, the 5-year survival rate is only approximately 30 to $40 \%(8,9,10)$. This is closely related to local recurrence and metastatic spread. Therefore, increased understanding of the risk factors of recurrence is essential to allow for the earliest possible diagnosis of DCC recurrence and for rapid implementation of chemotherapy or local treatment of liver metastases, such as radiofrequency ablation (11). To date, few studies have specifically focused on studying DCC within periampullary tumours. Previously published studies found a better survival for DCC than for PDAC, but those results were based on uncontrolled cohorts analyses $(12,13)$.

The aim of the present study was to examine the outcomes after PD for DCC with focus on the risk factors influencing recurrence and survival. In addition, this study aimed to compare differences in prognosis between patients with DCC and PDAC treated by curative PD based on a matching analysis using a propensity score. 


\section{MATERIALS AND METHODS}

All consecutive patients who underwent PD for periampullary cancers in a tertiary referral centre between January 2000 and April 2013 were extracted from a prospective maintained database and were analysed retrospectively. The diagnosis of periampullary cancers were suspected on preoperative imaging data or biopsy, but only DCC and PDAC pathologically confirmed on surgical specimens were included. Ampullary and duodenal carcinomas were excluded from the analysis. This work was conducted after approval by the institutional review board.

The data collected included demographics (age, sex, body mass index (BMI), American Society of Anaesthesiologists (ASA) score (14)), tumour type, lymph node status, duration of surgery, venous or arterial resection and reconstruction, concomitant abdominal surgery, and transfusion requirement. Postoperative pancreatic fistulas were included in the analysis and were classified according to the International Study Group of Pancreatic Fistula (ISGPF) classification (15). Incidences of delayed gastric emptying (DGE) were included in the analysis and were classified according to the International Study Group of Pancreatic Surgery classification (ISGPS) (16). In this study, only DGE of grades B and C were considered because the nasogastric tube was systematically left in place until postoperative day 5. Postpancreatectomy haemorrhage, including intra- and extraluminal bleeding according to the ISGPS definition; biliary fistula, defined as the presence of bile in the drainage fluid; and systemic infections, defined as the presence of infectious signs requiring the administration of systemic antibiotics, were also assessed. Perioperative mortality was defined as death during the initial hospital stay or by POD 30 or, if the patient was discharged, by POD 90 . Postoperative complications were summarized using the Clavien-Dindo classification system (17). 


\section{Surgery}

All PD were performed following the standard Whipple procedure and Child reconstruction by senior pancreatic surgeons. An initial superior mesenteric artery approach was performed systematically after 2006. All PD in periampullary carcinoma were standardized, including the same lymph node dissection. All patients had intraoperative frozen section examination of the proximal main bile duct and the pancreatic section of the specimen. If invaded, additional resection to achieve a negative margin was performed. During reconstruction, pancreatic duct intubation was left to the discretion of the operator, but was generally performed in cases with small duct size $(<3 \mathrm{~mm})$ or soft pancreatic texture. Since 2005 , a nasojejunal tube was systematically placed during surgery at $30 \mathrm{~cm}$ downstream from the gastrojejunostomy in the efferent jejunal limb for the administration of postoperative enteral nutrition.

\section{Pathology}

The histological diagnosis was established by an expert pathologist in bilio-pancreatic disease according to the macroscopic and microscopic aspect and immunohistochemistry (with cytokeratin 7 and 20). When distinction between DCC and PDAC was questionable, specimen was reviewed by a second pathologist who confirmed the diagnosis. Considering the microscopic margin involvement, pathologists used a definition based on a $1 \mathrm{~mm}$ clearance, to specify $\mathrm{R} 0$ resection.

\section{Follow-up protocol}

After resection, all patients were followed every 3 months. A computed tomography scan was systematically performed every 3 months during the first 2 years after surgery and every 6 months thereafter. Follow-up data were obtained through routine clinical visits or through personal contact. The end of follow-up was between 1 February 2014 and 1 April 2014 or was at the time of death. 


\section{Recurrence}

Recurrence was considered when new lesion was shown on imaging finding without histological confirmation. When recurrence was diagnosed, the treatment strategy was determined at a multidisciplinary collaborative meeting, which was attended by pancreatic surgeons, radiologists, oncologists and gastroenterologists. According to their general condition and the degree of disease extension, the patients were treated with chemotherapy, radiation therapy or radiofrequency ablation. Patients with general recurrence received systematic chemotherapy, using gemcitabine or gemcitabine plus oxaliplatin (GEMOX). For localized non-progressive liver metastases, the feasibility of radiofrequency ablation and surgical resection were systematically discussed.

\section{Statistical analysis}

Quantitative variables are expressed as the means \pm standard deviation (SD) or as medians and ranges and were compared using Student's t-test or the Wilcoxon test as appropriate. Qualitative variables are expressed as numbers and percentages and were compared using the Chi-squared or Fisher's exact test, as appropriate. Survival analysis was performed by Kaplan-Meier curve analysis (all patients were included in survival analysis, even those who died postoperatively), and the results were compared with the log-rank test. All variables with $\mathrm{p}<0.10$ by univariate analysis were entered into a multivariate model (i.e., COX proportional hazard model). The best final multivariate model was selected using a stepwise method in order to only retain variables with a p value of $<0.05$.

The propensity score was calculated for each patient and included variables known to significant influence outcomes (i.e., age, gender, BMI, $\mathrm{T}$ stage, $\mathrm{N}$ stage, microvascular invasion, perineural infiltration, necessity of vascular resection, and R0 resection achievement). Patients with DCC were matched to the closest patient with PDAC at a 1:1 ratio and then compared using the log-rank test.

A $\mathrm{p}$ value of $<0.05$ was considered statistically significant. All statistical analyses were performed using R statistical software, version 2.15.1 (http://www.r-project.org/). 


\section{RESULTS}

\section{Demographic and operative data}

During the study period, 290 patients underwent PD with curative intent for periampullary tumours, including 56 patients (19.3\%) treated for DCC (32 men, 24 women) and 182 patients (63\%) for PDAC (Figure 1). For the patients with DCC, the mean age at surgery was 65 years ( \pm 15.1 range: 40 - 86). Before surgery, endoscopic stenting was performed in 18 patients $(32.1 \%)$. The preoperative dilatation rate of the pancreatic duct was $28.6 \%$. None of the patients underwent preoperative chemotherapy.

The mean operative time was 327 min ( \pm 183 range: 170 - 590) (Table 3). The adjacent organ resection (colon, liver or liver and colon combination) and vascular resection were required for $8.9 \%$ and $16.1 \%$ of patients, respectively, for R0 resection. Patients requiring resections of adjacent organs had no postoperative complications related to this resection.

All patients had tumor free proximal bile duct margin, after frozen section analysis. Drainage of the pancreatic duct was performed in 36 patients $(64.3 \%)$.

The pathological findings showed that complete tumour removal (RO resection) was achieved in 49 patients $(87.5 \%)$. Lymph node metastasis was found in 28 patients $(50 \%)$. Vascular invasion was present in 16 patients $(28.6 \%)$, and perineural invasion was present in 23 patients $(41.1 \%)$.

The postoperative complications included pancreatic fistula in 7 patients (12.5\%), abdominal infection in 11 patients $(19.6 \%)$, bleeding in 13 patients $(23.2 \%)$. Reoperation was necessary in 12 patients $(21.4 \%) ; 11(92 \%)$ was linked either to a hematoma, or an active bleeding, one (8\%) reoperation was required to an isolated pancreatic fistula. The perioperative mortality was $7.1 \%$ at 30 days after the operation and $12.5 \%$ at 90 days after the operation. Postoperative chemotherapy was administered to 14 patients with DCC (25\%), while 36 patients with PDAC (64\%) received adjuvant chemotherapy. 


\section{Survival and recurrence rates}

The mean Follow-up was 28.8 months. The overall median survival (OS) was 36.9 months, with actuarial survival rates at 1,3 and 5 years of $74.5 \%, 31.8 \%$, and $27.1 \%$, respectively. The median disease-free survival (DFS) was 14.6 months, with actuarial survival rates at 1, 3 and 5 years of $57.1 \%, 31.8 \%$ and $19.7 \%$, respectively.

Recurrence occurred in 35 of the 52 patients $(67 \%)$ who were still alive after the postoperative period, with an mean delay of 13 months. The most frequent form of recurrence was isolated liver metastasis $(n=13,37 \%)$, followed by local recurrences $(n=9,26 \%)$, peritoneal carcinomatosis $(n=7,20 \%)$, and lung metastasis $(n=4,11 \%)$, and others locations $(n=2,6 \%)$. Details of recurrence are summarized in Figure 2. The treatments for recurrence were chemotherapy for 28 patients $(80 \%)$, chemotherapy combined with radiofrequency ablation for one patient $(2.9 \%)$, radiofrequency ablation for one patient $(2.9 \%)$ and radiotherapy for one patient $(2.9 \%)$.

\section{Factors influencing OS}

Of the 19 variables assessed by univariable analysis, need for organ resection $(p=0.032), R 1$ resection $(\mathrm{p}=0.003)$, tumour size $>2 \mathrm{~cm}(\mathrm{p}=0.047)$, vascular invasion $(\mathrm{p}=0.05)$, occurrence of postoperative haemorrhage $(\mathrm{p}=0.032)$ were significantly associated with a worse overall survival. On multivariate analysis, only need for organ resection (HR 4.31 [1.38 - 13.42], $\mathrm{p}=0.012), \mathrm{R} 1$ resection $(\mathrm{HR} 4.37$ [1.63 - 11.7], $\mathrm{p}=0.003)$ and postoperative haemorrhage (HR 1.45 [1.73 - 10.47], $\mathrm{p}=0.002$ ) remained significant independent factors influencing overall survival (Table 1). 


\section{Risk factors for recurrence}

The univariable analyses showed that male gender $(p=0.039)$, need for organ resection $(p=$ $0.001), R 1$ resection $(p=0.014)$, tumour size $>2 \mathrm{~cm}(p=0.05)$, vascular invasion $(p=0.012)$, postoperative abdominal infection $(\mathrm{p}=0.034)$, and occurrence of biliary fistula $(\mathrm{p}=0.013)$, were significantly related to DFS.

For the multivariable analysis, only male gender $(\mathrm{HR}=3.29[1.6-6.78], \mathrm{p}=0.001)$, need for organ resection $(\mathrm{HR}=7.1[2.17-23.23], \mathrm{p}=0.001)$, vascular invasion $(\mathrm{HR}=2.71[1.41-5.2])$ $\mathrm{p}=0.003)$, and abdominal infection after surgery $(\mathrm{HR}=3.39[1.46-7.88] \mathrm{p}=0.004)$ remained significant independent factors related to DFS (Table 2).

\section{Comparison of prognosis for DCC and PDAC}

The characteristics (e.g., demographic and perioperative data, pathological findings and postoperative outcomes) of the two matched groups are reported in table 3 . The propensity score matching (1:1) of patients who underwent PD for DCC and PDAC did not find any significant differences in OS $(p=0.284)$ or DFS $(p=0.438)$ (Figure 3$)$. When excluding patients who died in postoperative period $(n=4,7.1 \%)$, DCC and PDAC still have similar outcomes (Supplementary files, Figure 1). 


\section{DISCUSSION}

DCC is a tumour associated with poor prognosis due to the high rate of recurrence despite the performance of PD with curative intent. Few studies have specifically focused on oncological outcomes of resected DCC, and, in particular, few studies have tried to determine factors associated with recurrence. The present study focused on 56 patients who underwent PD for DCC with curative intent and provides two important sets of data. The first set of data showed that recurrence occurred frequently (67\%), precociously (13 months on average), and usually in the liver $(37 \%)$. The second set of data provided novel and important information concerning the true prognosis of resected DCC compared to that of resected PDAC. For the first time, the present analysis demonstrated that OS and DFS of resected DCC were similar to those of resected PDAC using a relevant method of matching based on a propensity score ( $\mathrm{p}=0.284, \mathrm{p}=0.43$, respectively).

Although PD is performed with curative intent, long-term overall and recurrence free survivals remain disappointing, and a better understanding of recurrence and its risk factors is necessary to identify high-risk individuals. To date, the independent factors that have been shown to likely be associated with the prognosis of DCC are vascular and perineural invasion, the status of the surgical margin and lymph node involvement $(9,18,19)$. In particular, the number of involved lymph nodes and its ratio (LNR) seems to be highly correlated with survival of resected DCC $(2,20-22)$. However, it is difficult to clearly identify a relevant cutoff value for the total number of involved lymph nodes because that number has not been comparable between different studies, and previous studies have had small sample sizes. While it is widely accepted that a examining a greater number of lymph nodes allows for more accurate staging, the number of involved nodes is not applied in the current American Joint Committee on Cancer (AJCC) TNM classification system for DCC, unlike in the classification systems for gastric and colorectal cancer. 
In the same regard, the current study systematically performed lymph node dissection and found that one half of patients had positive lymph node status, but the results did not confirm any impact of lymph node involvement on OS $(\mathrm{p}=0.38)$ or DFS (0.88). Similarly, Noji et al. demonstrated that extracapsular lymph node involvement had no impact on the survival $(\mathrm{p}=0.418)$ of DCC after resection with curative intent (23). The results of the present study support several other independent risk factors associated with poor DFS: i) male gender (HR= $3.29[1.6-6.78], p=0.001)$; ii) need for organ resection $(H R=7.1[2.17-23.23], p=0.001)$; iii) vascular invasion $(\mathrm{HR}=2.71[1.41-5.2]) \mathrm{p}=0.003)$; and iv) abdominal infection following surgery $(\mathrm{HR}=3.39[1.46-7.88] \mathrm{p}=0.004)$. These independent risk factors should allow for accurate identification of patients who should be closely monitored because they have a higher risk of recurrence. Adjuvant chemotherapy has previously been studied for its potential to improve survival in cholangiocarcinoma $(24,25)$. A prospective study of this approach (ClinicalTrials.gov identifier NCT01313377) is currently ongoing and aims to prevent and reduce the relapse rate of cholangiocarcinoma; however, as no recommendation for adjuvant chemotherapy in this setting is currently available, it was used at the discretion of the medical staff (oncologists and surgeons) involved in the care of the patients. This attitude is neither rational nor suitable, and the determination of which cholangiocarcinoma patients should receive adjuvant chemotherapy should be adjusted based on factors related to recurrence. In fact, for the high risk group of patients, it would seem beneficial to provide adjuvant chemotherapy after curative PD.

This study also provides important information regarding the types of recurrence of DCC. The liver has been previously been reported as the most common site of disease spread, and this is in agreement with the present results. Takao and al. were the first to demonstrate that liver recurrence after R0 resection occurred significantly more frequently than other types of recurrence (21 patients among $64,33 \%, \mathrm{p}<0.05)(26)$. 
This finding has since been widely confirmed by other teams $(27,28)$. In addition, liver metastasis occurs at a higher rate in resected DCC than in resected ampullary cancer $(24 \% \mathrm{vs}$ $10 \%, p=0.004)$, but the overall recurrence rates of these two cancers were similar, suggesting the liver tropism of metastases from DCC such as the other biliary cancer (19). To date, there is no recommendation for the treatment of DCC recurrence, and in particularly, no relevant strategy is currently available for the treatment of localized liver metastases. The results of the present study perfectly illustrate this fact, as patients received equal benefits from chemotherapy, combined chemotherapy-radiotherapy and radiofrequency ablation, which were performed in $85 \%, 1.8 \%$ and $1.8 \%$ of patients, respectively. Aggressive treatment approaches for liver metastases after curative resection of DCC (radiofrequency ablation and liver resection) have not been currently assessed or discussed in the literature. In contrast, aggressive treatment approaches have been examined for their possible ability to prolong survival in patients with liver metastases originating from cholangiocarcinomas with other primary locations than those of DCC $(29,30)$. It would be valuable to explore aggressive treatment approaches for liver metastases originating from DCC in the near future to improve the prognosis of this disease.

DCC has often been considered to have better prognosis than PDAC. However, studies that have compared the long-term outcomes of patients with resected DCC and resected PDAC are rare, and comparative reports with relevant matching do not exist. The current report demonstrates for the first time that patients who underwent PD with curative intent for DCC or PDAC had the same prognosis, with no significant differences in OS or DFS. Based on the results of the current study, DCC may even have a worse prognosis than PDAC because most cases of resected DCC did not receive adjuvant therapy unlike for cases of resected PDAC. This further strengthens the critical need for the discovery of new therapeutic targets for adjuvant therapy in DCC. 
The present study showed that DCC could not be considered as small lesion as the median size was 2.71 centimetres. This finding is consistent with previously reported studies $(13,20)$ and could be a potential explanation of the dismal prognosis observed. Indeed, a median size higher than 2 centimetres was associated with worst OS and DFS in univariate analysis but was not confirmed in multivariable analysis.

Of course, some possible weaknesses of the present study should be mentioned. First, the present results are based on a single centre series with a limited sample size and a long period of recruitment. However, the low incidence of DCC partly explains the necessity of the long duration of recruitment and the small sample size of this study, which was comparable to or not higher than those of previous studies. Moreover, the mean reported follow up (i.e. 28.8 months) is similar to previous study $(9,22)$. Second, even though data were extracted from a maintained prospective database, the statistical analysis was performed retrospectively. These factors may have generated some bias and, therefore, the results of this study must be confirmed by larger studies in the future.

The present study generated new interesting sets of data regarding the oncological outcomes of resected DCC. First, the characterization of recurrence, including risk factors that could better define a high risk group was presented. Second, the true oncological outcomes of DCC were compared to those of PDAC, which are two cancers that have the same prognosis. Both increased use of adjuvant therapy and the evaluation of aggressive treatment of liver metastases are necessary to improve the survival of patients with resected DCC. 


\section{REFERENCES}

1. Razumilava N, Gores GJ. Classification, diagnosis, and management of cholangiocarcinoma. Clin Gastroenterol Hepatol Off Clin Pract J Am Gastroenterol Assoc. 2013 Jan;11(1):13-21.e1; quiz e3-4.

2. Tol J a. MG, Brosens L a. A, van Dieren S, van Gulik TM, Busch ORC, Besselink MGH, et al. Impact of lymph node ratio on survival in patients with pancreatic and periampullary cancer. $\mathrm{Br}$ J Surg. 2015 Feb;102(3):237-45.

3. Nakase A, Matsumoto Y, Uchida K, Honjo I. Surgical treatment of cancer of the pancreas and the periampullary region: cumulative results in 57 institutions in Japan. Ann Surg. 1977 Jan; 185(1):52-7.

4. Blechacz B, Komuta M, Roskams T, Gores GJ. Clinical diagnosis and staging of cholangiocarcinoma. Nat Rev Gastroenterol Hepatol. 2011 Sep;8(9):512-22.

5. Turaga KK, Tsai S, Wiebe LA, Evans DB, Gamblin TC. Novel multimodality treatment sequencing for extrahepatic (mid and distal) cholangiocarcinoma. Ann Surg Oncol. 2013 Apr;20(4):1230-9.

6. Penz M, Kornek GV, Raderer M, Ulrich-Pur H, Fiebiger W, Lenauer A, et al. Phase II trial of two-weekly gemcitabine in patients with advanced biliary tract cancer. Ann Oncol Off J Eur Soc Med Oncol ESMO. 2001 Feb;12(2):183-6.

7. Oshiro Y, Takahashi K, Sasaki R, Kondo T, Sakashita S, Ohkohchi N. Adjuvant surgery for advanced extrahepatic cholangiocarcinoma. World J Gastroenterol WJG. 2013 Oct 28;19(40):6934-8.

8. Van der Gaag NA, Kloek JJ, de Bakker JK, Musters B, Geskus RB, Busch ORC, et al. Survival analysis and prognostic nomogram for patients undergoing resection of extrahepatic cholangiocarcinoma. Ann Oncol Off J Eur Soc Med Oncol ESMO. 2012 Oct;23(10):2642-9.

9. Qiao Q-L, Zhang T-P, Guo J-C, Zhan H-X, Zhao J-X, Liu Y-C, et al. Prognostic factors after pancreatoduodenectomy for distal bile duct cancer. Am Surg. 2011 Nov;77(11):1445-8.

10. Murakami Y, Uemura K, Sudo T, Hashimoto Y, Nakashima A, Kondo N, et al. Prognostic factors after surgical resection for intrahepatic, hilar, and distal cholangiocarcinoma. Ann Surg Oncol. 2011 Mar;18(3):651-8.

11. Park S, Kim JH, Won HJ, Shin YM, Kim PN. Radiofrequency ablation of hepatic metastases after curative resection of extrahepatic cholangiocarcinoma. AJR Am J Roentgenol. 2011 Dec;197(6):W1129-34.

12. Dickson PV, Behrman SW. Distal cholangiocarcinoma. Surg Clin North Am. 2014 Apr;94(2):325-42.

13. Hatzaras I, George N, Muscarella P, Melvin WS, Ellison EC, Bloomston M. Predictors of survival in periampullary cancers following pancreaticoduodenectomy. Ann Surg Oncol. 2010 Apr;17(4):991-7.

14. Owens WD, Felts JA, Spitznagel EL. ASA physical status classifications: a study of consistency of ratings. Anesthesiology. 1978 Oct;49(4):239-43.

15. Bassi C, Dervenis C, Butturini G, Fingerhut A, Yeo C, Izbicki J, et al. Postoperative pancreatic fistula: an international study group (ISGPF) definition. Surgery. 2005 Jul;138(1):8-13. 
16. Wente MN, Bassi C, Dervenis C, Fingerhut A, Gouma DJ, Izbicki JR, et al. Delayed gastric emptying (DGE) after pancreatic surgery: a suggested definition by the International Study Group of Pancreatic Surgery (ISGPS). Surgery. 2007 Nov;142(5):761-8.

17. Dindo D, Demartines N, Clavien P-A. Classification of surgical complications: a new proposal with evaluation in a cohort of 6336 patients and results of a survey. Ann Surg. 2004 Aug;240(2):205-13.

18. Kayahara M, Nagakawa T, Ohta T, Kitagawa H, Tajima H, Miwa K. Role of nodal involvement and the periductal soft-tissue margin in middle and distal bile duct cancer. Ann Surg. 1999 Jan;229(1):76-83.

19. Woo SM, Ryu JK, Lee SH, Yoo JW, Park JK, Kim Y-T, et al. Recurrence and prognostic factors of ampullary carcinoma after radical resection: comparison with distal extrahepatic cholangiocarcinoma. Ann Surg Oncol. 2007 Nov;14(11):3195-201.

20. Kiriyama M, Ebata T, Aoba T, Kaneoka Y, Arai T, Shimizu Y, et al. Prognostic impact of lymph node metastasis in distal cholangiocarcinoma. Br J Surg. 2015 Mar;102(4):399-406.

21. Ito K, Ito H, Allen PJ, Gonen M, Klimstra D, D'Angelica MI, et al. Adequate lymph node assessment for extrahepatic bile duct adenocarcinoma. Ann Surg. 2010 Apr;251(4):675-81.

22. Murakami Y, Uemura K, Hayashidani Y, Sudo T, Ohge H, Sueda T. Pancreatoduodenectomy for distal cholangiocarcinoma: prognostic impact of lymph node metastasis. World J Surg. 2007 Feb;31(2):337-42; discussion 343-4.

23. Noji T, Miyamoto M, Kubota KC, Shinohara T, Ambo Y, Matsuno Y, et al. Evaluation of extra capsular lymph node involvement in patients with extra-hepatic bile duct cancer. World J Surg Oncol. 2012;10:106.

24. Hernandez J, Cowgill SM, Al-Saadi S, Villadolid D, Ross S, Kraemer E, et al. An aggressive approach to extrahepatic cholangiocarcinomas is warranted: margin status does not impact survival after resection. Ann Surg Oncol. 2008 Mar;15(3):807-14.

25. Horgan AM, Amir E, Walter T, Knox JJ. Adjuvant therapy in the treatment of biliary tract cancer: a systematic review and meta-analysis. J Clin Oncol Off J Am Soc Clin Oncol. 2012 Jun 1;30(16):1934-40.

26. Takao S, Shinchi H, Uchikura K, Kubo M, Aikou T. Liver metastases after curative resection in patients with distal bile duct cancer. Br J Surg. 1999 Mar;86(3):327-31.

27. Todoroki T, Kawamoto T, Koike N, Fukao K, Shoda J, Takahashi H. Treatment strategy for patients with middle and lower third bile duct cancer. Br J Surg. 2001 Mar;88(3):364-70.

28. Choi SB, Park SW, Kim KS, Choi JS, Lee WJ. The survival outcome and prognostic factors for middle and distal bile duct cancer following surgical resection. J Surg Oncol. 2009 May $1 ; 99(6): 335-42$.

29. Ercolani G, Vetrone G, Grazi GL, Aramaki O, Cescon M, Ravaioli M, et al. Intrahepatic cholangiocarcinoma: primary liver resection and aggressive multimodal treatment of recurrence significantly prolong survival. Ann Surg. 2010 Jul;252(1):107-14.

30. Sulpice L, Rayar M, Boucher E, Pracht M, Meunier B, Boudjema K. Treatment of recurrent intrahepatic cholangiocarcinoma. Br J Surg. 2012 Dec;99(12):1711-7. 
FIGURE LEGENDS

Figure 1. Patient selection flowchart

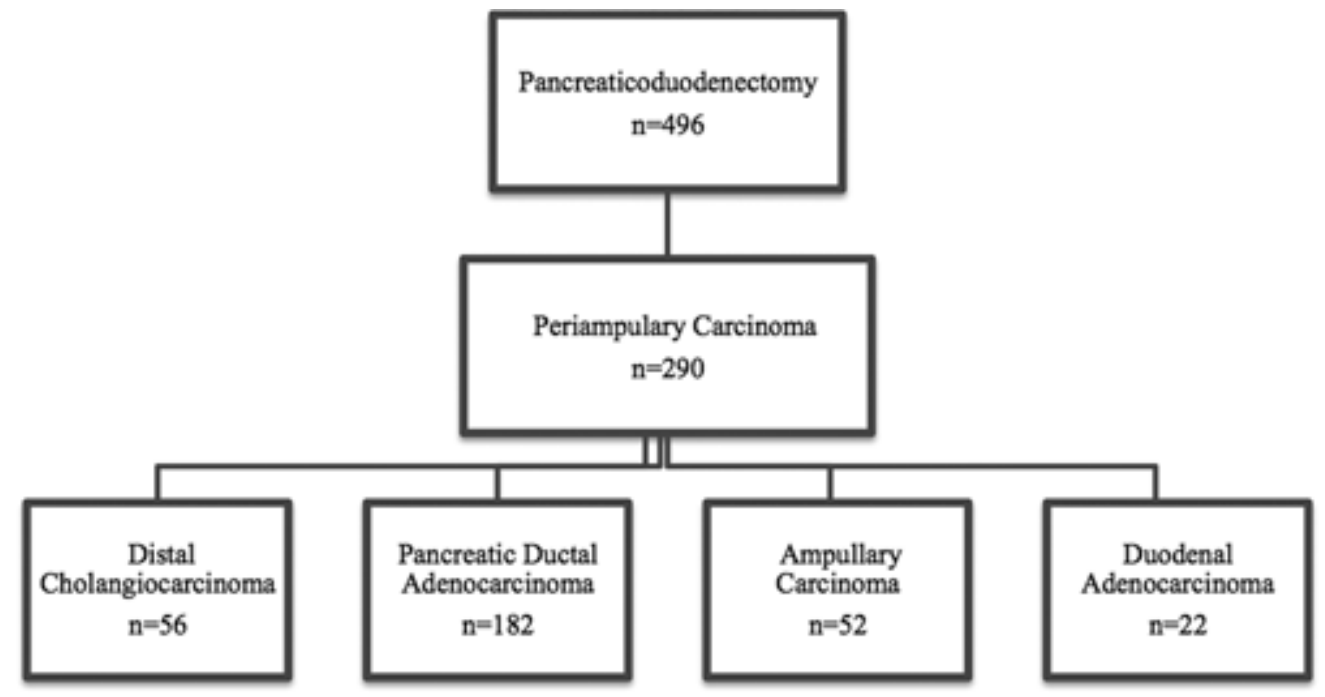

Figure 2. Characteristics of recurrences.

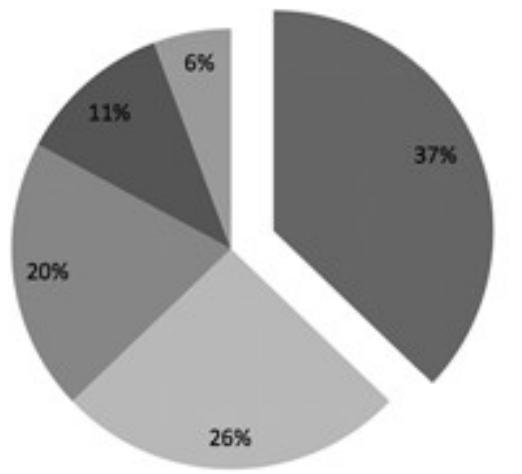

$$
\begin{aligned}
& \text { "Liver } \\
& =\text { Local } \\
& \text { = Carcinomatosis } \\
& \text { = Lung } \\
& \text { = Others }
\end{aligned}
$$


Figure 3. Overall and disease-free survivals compared between patients who underwent PD with curative intent for DCC (red line) and PDAC (black line). (A) Overall survival. (B) Disease-free survival. a $\mathrm{p}=\mathbf{0 . 2 8 4}, \mathrm{b} \mathrm{p}=\mathbf{0 . 4 3}$.
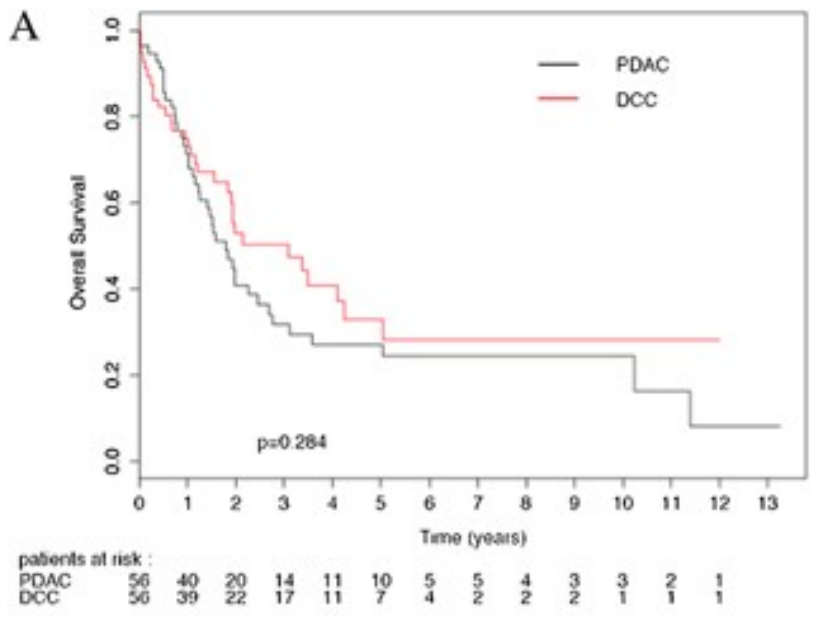

B

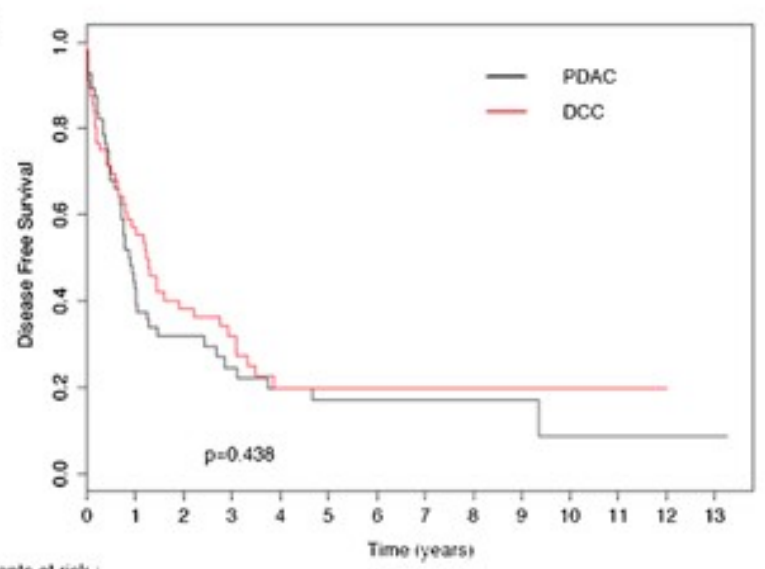

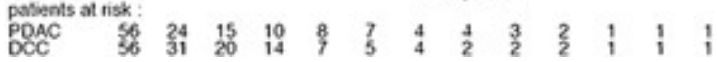


Table 1. Univariable and multivariable analyses of clinicopathological factors that may influence overall survival.

TABLE I. Patient Characteristics of the Two Matched Groups (DCC and PDAC)

\begin{tabular}{|c|c|c|c|}
\hline \multirow[b]{2}{*}{ Variables } & \multirow{2}{*}{$\begin{array}{c}\text { DCC } \\
\mathrm{n}=56\end{array}$} & \multirow{2}{*}{$\begin{array}{l}\text { PDAC } \\
\mathrm{n}=56\end{array}$} & \multirow[b]{2}{*}{$P$-value } \\
\hline & & & \\
\hline \multicolumn{4}{|l|}{ Preoperative } \\
\hline Sex ratio $(\mathrm{F}: \mathrm{M})$ & $24: 32$ & $24: 32$ & 1 \\
\hline Age (mean $\pm S D$, years $)$ & $65 \pm 15$ & $65 \pm 14$ & 0.97 \\
\hline $\mathrm{BMI}\left(\operatorname{mean} \pm \mathrm{SD}, \mathrm{kg} / \mathrm{m}^{2}\right)$ & $25.5 \pm 7.6$ & $25 \pm 6.6$ & 0.86 \\
\hline \multicolumn{4}{|l|}{ ASA score } \\
\hline 0 & $1(1.8)$ & $1(1.8)$ & \\
\hline 1 & $12(21.4)$ & $13(23.2)$ & \\
\hline 2 & $32(57.1)$ & $37(66.1)$ & \\
\hline 3 & $11(19.6)$ & $5(8.9)$ & \\
\hline Biliary dilatation & $36(64.3)$ & $33(58.9)$ & 0.7 \\
\hline Pancreatic dilatation & $16(28.6)$ & $22(39.3)$ & 0.32 \\
\hline Jaundice & $49(87.5)$ & $39(69.6)$ & 0.04 \\
\hline Biliary stent & $18(32.1)$ & $18(32.1)$ & 1 \\
\hline \multicolumn{4}{|l|}{ Surgery } \\
\hline Operative time (min) & $327 \pm 182$ & $339 \pm 179$ & 0.54 \\
\hline Adjacent organ resection & $5(8.9)$ & $6(10.7)$ & 1 \\
\hline Vascular resection & $9(16.1)$ & $15(26.8)$ & 0.25 \\
\hline \multicolumn{4}{|l|}{ Pathology } \\
\hline $\mathrm{R} 1$ resection & $7(12.5)$ & $8(14.3)$ & 1 \\
\hline Tumor size $(\mathrm{cm})$ & $2.71 \pm 4.8$ & $2.72 \pm 1.5$ & 0.13 \\
\hline Lymph node invasion & $28(50)$ & $29(51.8)$ & 1 \\
\hline Microvascular invasion & $16(28.6)$ & $18(32.1)$ & 0.84 \\
\hline Perineural infiltration & $23(41.1)$ & $28(50)$ & 0.45 \\
\hline \multicolumn{4}{|l|}{ Postoperative } \\
\hline Abdominal infection & $11(19.6)$ & $6(10.7)$ & 0.29 \\
\hline Delayed gastric emptying & $39(69.6)$ & $43(76.8)$ & 0.52 \\
\hline Biliary fistula & $1(1.8)$ & $0(0)$ & 1 \\
\hline Pancreatic fistula & $7(12.5)$ & $8(14.3)$ & 1 \\
\hline Postoperative haemorrhage & $13(23.2)$ & $3(5.4)$ & 0.01 \\
\hline Blood transfusion & $24(42.9)$ & $33(58.9)$ & 0.13 \\
\hline Clavien grade $\geq 3$ & $14(25)$ & $6(10.7)$ & 0.08 \\
\hline Duration of hospital stay (days) & $14(7.75)$ & $15(8.76)$ & 0.84 \\
\hline Mortality at 30 days & $4(7.1)$ & $2(3.6)$ & 0.68 \\
\hline
\end{tabular}

The values given are numbers (percentages). BMI, body mass index; ASA, American Society of Anesthesiologists. 
Table 2. Univariable and multivariable analyses of clinicopathological factors that may influence disease-free survival.

TABLE II. Univariable and Multivariable Analyses of Clinicopathological Factors That May Influence Overall Survival

\begin{tabular}{|c|c|c|c|}
\hline \multirow[b]{2}{*}{ Variables } & \multirow{2}{*}{$\frac{\text { Univariable }}{P \text {-value }}$} & \multicolumn{2}{|c|}{ Multivariable } \\
\hline & & $\mathrm{HR}^{\mathrm{b}}$ & $P$-value ${ }^{c}$ \\
\hline \multicolumn{4}{|l|}{ Preoperative } \\
\hline Gender & 0.06 & $2.53[1.1-5.7]$ & 0.03 \\
\hline Age $\geq 70$ years & 0.93 & - & - \\
\hline $\mathrm{BMI} \geq 30 \mathrm{~kg} / \mathrm{m}^{2}$ & 0.82 & - & - \\
\hline ASA score $>1$ & 0.86 & - & - \\
\hline Jaundice & 0.87 & - & - \\
\hline Biliary stent & 0.02 & ns & ns \\
\hline \multicolumn{4}{|l|}{ Surgery } \\
\hline Adjacent organ resection & 0.03 & $4.31[1.4-13.4]$ & 0.01 \\
\hline Vascular resection & 0.17 & $\mathrm{~ns}$ & $\mathrm{~ns}$ \\
\hline \multicolumn{4}{|l|}{ Pathology } \\
\hline $\mathrm{R} 1$ resection & 0.003 & $4.37[1.6-11.7]$ & 0.003 \\
\hline Tumor size $>2 \mathrm{~cm}$ & 0.05 & ns & ns \\
\hline Lymph node invasion & 0.38 & - & - \\
\hline Microvascular invasion & 0.06 & ns & ns \\
\hline Perineural infiltration & 0.63 & - & - \\
\hline \multicolumn{4}{|l|}{ Postoperative } \\
\hline Abdominal infection & 0.83 & - & - \\
\hline Biliary fistula & 0.06 & ns & ns \\
\hline Pancreatic fistula & 0.7 & - & - \\
\hline Postoperative haemorrhage & 0.03 & $1.45[1.7-10.5]$ & 0.002 \\
\hline Blood transfusion & 0.49 & ns & ns \\
\hline Postoperative chemotherapy & 0.32 & - & - \\
\hline
\end{tabular}

${ }^{\mathrm{a}} \mathrm{Log}$ rank test.

${ }^{\mathrm{b}} 95 \%$ confidence intervals.

${ }^{\mathrm{c}} \mathrm{Cox}$ model. 
Table 3. Patient characteristics of the two matched groups (DCC and PDAC).

TABLE III. Univariable and Multivariable Analyses of Clinicopathological Factors That May Influence Disease-Free Survival

\begin{tabular}{|c|c|c|c|}
\hline \multirow[b]{2}{*}{ Variables } & \multirow{2}{*}{$\frac{\text { Univariable }}{P \text {-value }}$} & \multicolumn{2}{|c|}{ Multivariable } \\
\hline & & $\mathrm{HR}^{\mathrm{b}}$ & $P$-value ${ }^{\mathrm{c}}$ \\
\hline \multicolumn{4}{|l|}{ Preoperative } \\
\hline Gender & 0.04 & $3.29[1.6-6.8]$ & 0.001 \\
\hline Age $\geq 70$ years & 0.93 & - & - \\
\hline $\mathrm{BMI}>30 \mathrm{~kg} / \mathrm{m}^{2}$ & 0.22 & - & - \\
\hline ASA $\overline{\text { score }>1}$ & 0.98 & - & - \\
\hline Jaundice & 0.42 & - & - \\
\hline Biliary stent & 0.12 & - & - \\
\hline \multicolumn{4}{|l|}{ Surgery } \\
\hline Adjacent organ resection & 0.001 & $7.1[2.2-23.2]$ & 0.001 \\
\hline Vascular resection & 0.15 & - & - \\
\hline \multicolumn{4}{|l|}{ Pathology } \\
\hline $\mathrm{R} 1$ resection & 0.01 & ns & ns \\
\hline Tumor size $>2 \mathrm{~cm}$ & 0.05 & ns & ns \\
\hline Microvascular invasion & 0.01 & $2.71[1.4-5.2]$ & 0.003 \\
\hline Lymph node invasion & 0.88 & - & - \\
\hline Perineural infiltration & 0.25 & - & - \\
\hline \multicolumn{4}{|l|}{ Postoperative } \\
\hline Abdominal infection & 0.03 & $3.39[1.5-7.9]$ & 0.004 \\
\hline Biliary fistula & 0.01 & ns & ns \\
\hline Pancreatic fistula & 0.52 & - & - \\
\hline Postoperative haemorrhage & 0.23 & - & - \\
\hline Blood transfusion & 0.76 & - & - \\
\hline Postoperative chemotherapy & 0.82 & ns & ns \\
\hline
\end{tabular}

${ }^{a}$ Log rank test.

${ }^{\mathrm{b}} 95 \%$ confidence intervals.

${ }^{\mathrm{c}}$ Cox model. 


\section{SUPPLEMENTARY FILES}

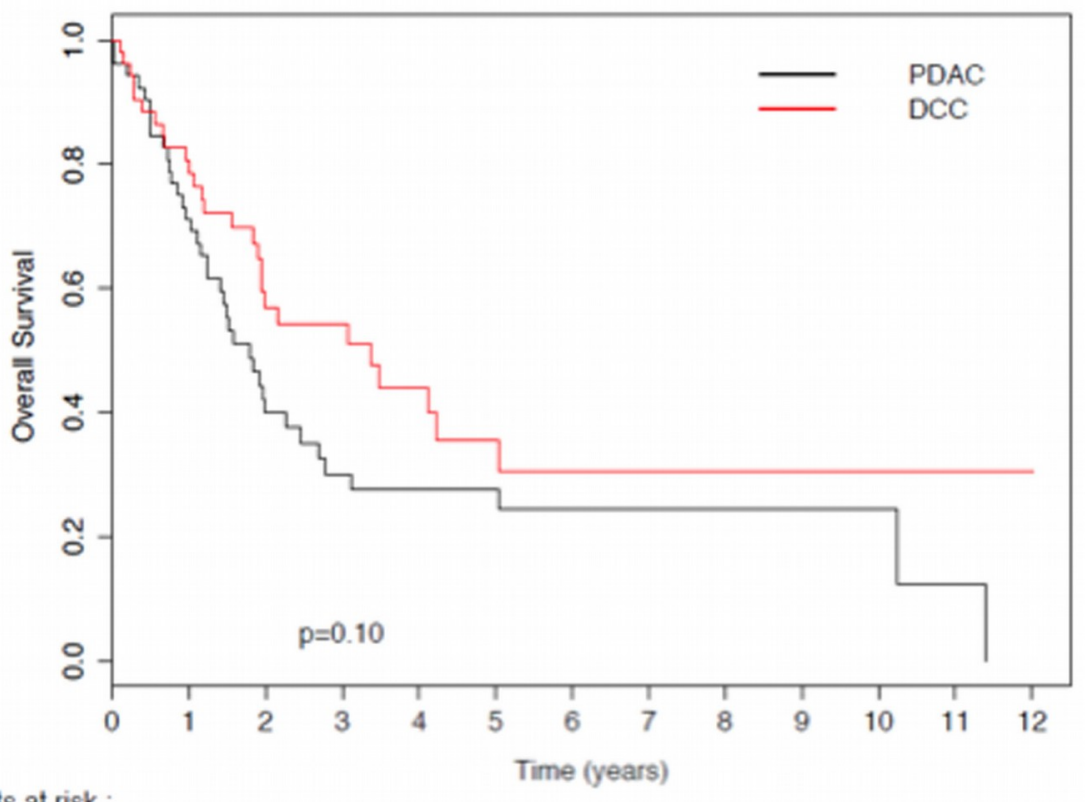

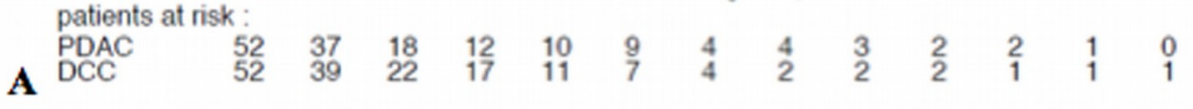

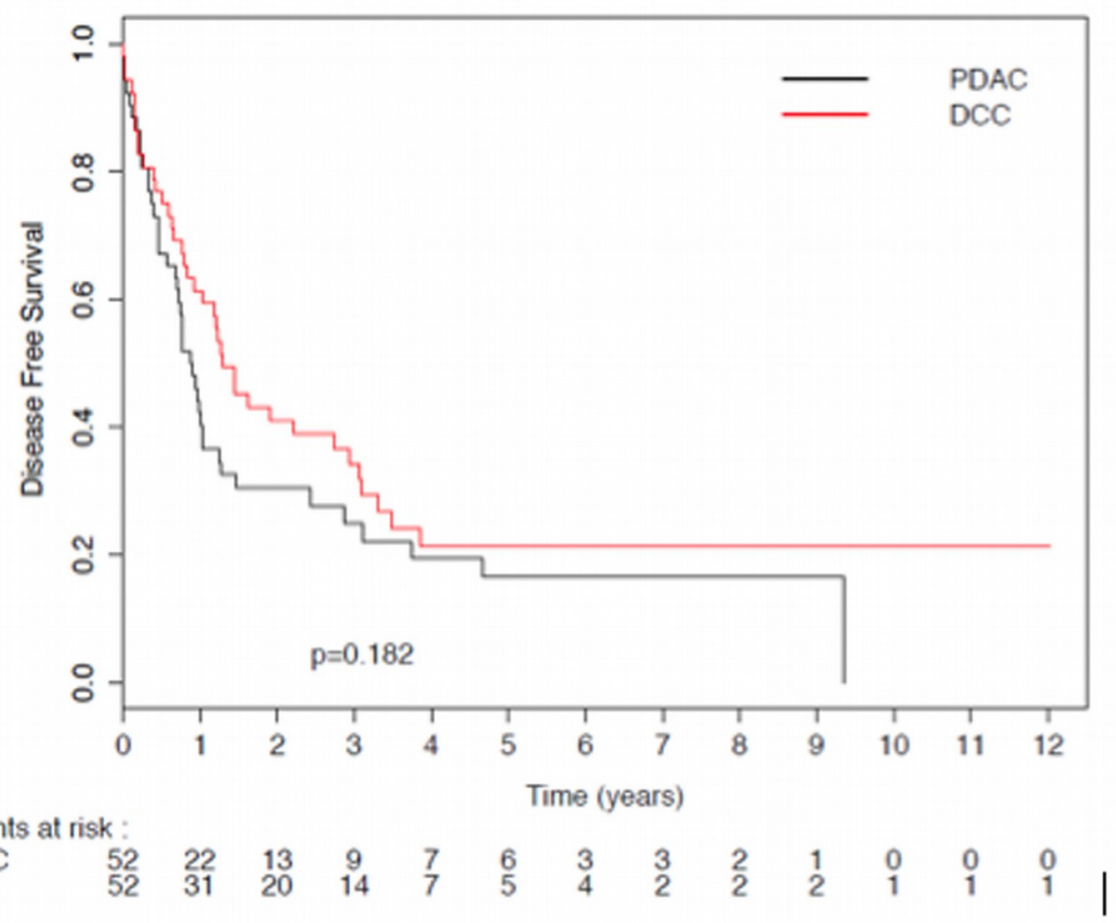

Figure 1. Overall and disease-free survivals compared between patients who underwent PD with curative intent for DCC (red line) and PDAC (black line), after excluding the 4 DCC died postoperatively. (A) Overall survival. (B) Disease-free survival. a $p=0.10$, b $\mathrm{p}=\mathbf{0 . 1 8 2}$. 